\title{
Efeito do meio de cultura e do regime de luz na esporulação de Cercospora zeae-maydis
}

\author{
Kátia Regiane Brunelli1,2, Ana Carolina Fazza' ${ }^{1}$, Cândido Athayde Sobrinho',3, Luis Eduardo Aranha Camargo ${ }^{1}$ \\ ${ }^{1}$ Departamento de Entomologia, Fitopatologia e Zoologia Agrícola - ESALQ-USP, CP 9, 13418-900, Piracicaba, SP; <krbrunelli@ yahoo.com.br> . \\ ${ }^{2}$ Bolsista CAPES. ${ }^{3}$ Embrapa Meio-Norte, CP 01, 64006-220, Teresina - PI, bolsista CNPq. Parte da Tese de Doutorado da primeira autora. \\ Autor para correspondência: Kátia Regiane Brunelli. <krbrunelli@yahoo.com.br>. \\ Data de chegada: 09/08/04. Aceito para publicação em: 15/08/05.
}

\begin{abstract}
Brunelli, K.R.; Fazza, A.C.; Athayde Sobrinho, C.; Camargo, L.E.A. Effect of culture media and light exposure on the sporulation of Cercospora zeae-maydis. Summa Phytopatologica, v. 32, p. 92-94, 2006.

Some fungal species, like Cercospora zeae-maydis, causal agent of maize gray leaf spot, do not satisfactorily produce spores in artificial media. The conidial production of $C$. zeae-maydis was evaluated on seven culture media (V8, tomato juice, coconut water, oat, PDA, maize leaf extract and maize leaf extract plus $\mathrm{CaCO}_{3}$ ) under two light exposure regimens (12-hours photoperiod or six days under continuous light followed by three days of continuous darkness). The experiment was

arranged as a $7 \times 2$ factorial design in a completely randomized design with five replicates. A single petri dish containing $20 \mathrm{~mL}$ of culture media inoculated with $200 \mu \mathrm{L}$ of conidial suspension $\left(8 \times 10^{4}\right.$ conidia/ $\mathrm{mL}$ ) comprised the experimental unit. Plates were incubated at $27^{\circ} \mathrm{C}$ for nine days. The highest conidial production was obtained on V8 and tomato juice media under 12-hours photoperiod, resulting in the production of 22.4 and $28.62 \times 10^{4}$ conidia/mL respectively.
\end{abstract}

Additional keywords: Zea mays, maize, gray leaf spot.

\section{RESUMO}

Brunelli, K.R.; Fazza, A.C.; Athayde sobrinho, C.; Camargo, L.E.A. Efeito do meio de cultura e do regime de luz na esporulação de Cercospora zeaemaydis. Summa Phytopatologica, v. 32, p. 92-94, 2006.

Algumas espécies fúngicas não esporulam satisfatoriamente em meio de cultura, a exemplo de Cercospora zeae-maydis, agente causal da cercosporiose do milho. A esporulação deste patógeno foi avaliada em sete meios de cultura agarizados (V8, suco de tomate temperado, água de coco, aveia, BDA, extrato de folha de milho e extrato de folha de milho $+\mathrm{CaCO}_{3}$ ) sob dois regimes luminosos (fotoperíodo de 12 horas e seqüencial - 6 dias claro/3 dias escuro). $\mathrm{O}$ ensaio foi conduzido em esquema fatorial 7 × 2, com os tratamentos dispostos em delineamento inteiramente casualizado com cinco repetições. A parcela experimental compreendeu uma placa de petri contendo $20 \mathrm{~mL}$ de meio de cultura sobre o qual foram colocados $200 \mu \mathrm{L}$ de uma suspensão de $8 \times 10^{4}$ esporos $/ \mathrm{mL}$. As culturas foram posteriormente incubadas a $27^{\circ} \mathrm{C} \mathrm{du}-$ rante nove dias. Os meios V8 e suco de tomate temperado (STT) sob regime de fotoperíodo $12 \mathrm{~h} / 12 \mathrm{~h}$, foram aqueles que apresentaram melhor indução de esporulação, resultando na produção de 22,4 x $10^{4}$ conídios/ mL e $28,62 \times 10^{4}$ conídios/mL, respectivamente.

Palavras-chave: Zea mays, milho, mancha de cercospora.

Cercospora zeae-maydis Tehon \& Daniels é um importante patógeno da cultura do milho, causando a doença foliar conhecida como mancha de cercospora ou cercosporiose. Sob condições ambientais adequadas e hospedeiro suscetível já foram relatados danos de até $65 \%$ na produção (10). Essa redução devese basicamente à indução precoce de senescência na planta causada pelo abundante número de lesões. No Brasil, esta doença causou sérias epidemias nas safras de 2000/2001, quando muitos dos híbridos mostraram-se suscetíveis. Nas safras de 2002/
2003, a mancha de cercospora foi controlada, em parte, pelo emprego de híbridos resistentes. Porém, em algumas regiões de Goiás e Minas Gerais, o patógeno ainda causa danos significativos à produção. Como o controle da doença é realizado, prioritariamente, pelo uso de híbridos resistentes, a determinação de condições ótimas para a produção de esporos in vitro é importante para trabalhos que utilizam inoculação artificial para identificar genótipos resistentes ao patógeno.

Espécies do gênero Cercospora caracterizam-se pelo lento 
crescimento e pela reduzida esporulação em meios de cultura. Agentes físicos são capazes de induzir ou inibir o desenvolvimento vegetativo e reprodutivo da maioria dos fungos, dentre eles os mais importantes são a temperatura e a luminosidade. A temperatura modula a produção de proteínas e enzimas responsáveis pela manutenção da célula fúngica (2). Estudos envolvendo espécies de Cercospora demonstram que temperaturas entre 25 e $27^{\circ} \mathrm{C}$ são ideais para produção de esporos $(1,6)$. A luminosidade exerce efeito direto sobre a célula fúngica, induzindo ou inibindo a formação de estruturas de reprodução, embora haja algumas espécies que são indiferentes à quantidade e/ ou qualidade da luz (4). Este trabalho teve por objetivo selecionar combinações de meios de cultura e regime luminoso que promovam abundante esporulação de $C$. zeae-maydis.

Os meios de cultura utilizados foram: V8 $(200 \mathrm{~mL}$ de suco de vegetais V8 “Campbell Soup Co."; $16 \mathrm{~g}$ de ágar; $3,2 \mathrm{~g}$ de $\mathrm{CaCO}_{3}$ e $800 \mathrm{~mL}$ de água destilada), STT (200 $\mathrm{mL}$ de suco de tomate

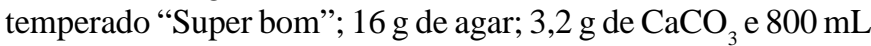
de água destilada), $\mathrm{AV}$ ( $20 \mathrm{~g}$ de farinha de aveia "Otker"; $16 \mathrm{~g}$ de ágar e $1000 \mathrm{~mL}$ de água), CO (1000 mL de água de coco "Sococo" e $16 \mathrm{~g}$ de ágar), FM (extrato de $80 \mathrm{~g}$ de folha de milho picada e levada ao fogo até levantar fervura; $16 \mathrm{~g}$ de ágar e água até completar $1000 \mathrm{~mL}$ ), $\mathrm{FM}-\mathrm{CaCO}_{3}\left(\mathrm{FM}+3,2 \mathrm{~g} \mathrm{de} \mathrm{CaCO}_{3}\right)$ e BDA (extrato de $200 \mathrm{~g}$ de batata; $20 \mathrm{~g}$ de dextrose; $16 \mathrm{~g}$ de ágar e água até completar o volume de $1000 \mathrm{~mL}$ ). Após o preparo, estes meios foram autoclavados a $121^{\circ} \mathrm{C}$ por 20 minutos e vertidos assepticamente em placas de petri.

O isolado monospórico IN-5 utilizado neste ensaio foi obtido por isolamento direto a partir de folha com sintoma típico da doença coletada em campo de produção no município de Indianópolis (MG). Este isolado foi cultivado em meio V8 durante nove dias, sob fotoperíodo $12 \mathrm{~h} / 12 \mathrm{~h}$ (12 horas de claro seguido de 12 horas de escuro), até a formação de esporos. Foi preparada uma suspensão de $8 \times 10^{4}$ esporos $/ \mathrm{mL}$ e $200 \mu \mathrm{L}$ foram depositados em cada placa de petri contendo $20 \mathrm{~mL}$ de meio de cultura. Estas foram incubadas durante nove dias sob um dos regimes de luminosidade: fotoperíodo $12 \mathrm{~h} / 12 \mathrm{~h}$ ou seqüencial com seis dias de claro contínuo seguido por três dias de escuro. As colônias foram incubadas em câmaras de crescimento (Tecnal TE400) à temperatura de $27^{\circ} \mathrm{C}$.

O ensaio foi conduzido em esquema fatorial 7 × 2 (meios de cultura $\mathrm{x}$ luminosidade), totalizando 14 tratamentos com cinco repetições, em delineamento inteiramente casualizado. Cada parcela consistiu de uma placa de petri.

Decorrido o período de incubação, as placas receberam 10 $\mathrm{mL}$ de água destilada contendo $0,01 \%$ de Tween 20 e, com o auxílio de uma lâmina de vidro, as colônias foram delicadamente raspadas para liberação dos conídios. A suspensão foi filtrada em camada dupla de gaze para retenção dos fragmentos miceliais e restos de meio de cultura. $\mathrm{O}$ número de conídios de cada parcela foi determinado ao microscópio ótico com auxílio de hemacitômetro. Os dados da contagem conidial de cada parcela foram transformados para $\sqrt{(x+1)}$ e submetidos a análise de variância. As médias dos tratamentos foram comparadas entre si pelo teste de Tukey em nível de 1\% de significância, com o auxílio do programa estatístico SAS (versão 6.2 - SAS Institute, Cary, NC).

Houve diferenças significativas entre tratamentos com relação à esporulação de C. zeae-maydis (Tabela 1). As colônias fúngicas formadas nos meios V8, STT, AV e CO apresentaram grande quantidade de conidióforos, mas apenas os meios V8 e STT induziram abundante formação de esporos, tanto sob fotoperíodo quanto sob regime de luz seqüencial (Tabela 1). O meio BDA estimulou a formação de pequena quantidade de conidióforos. Já nos meios $\mathrm{FM}$ e $\mathrm{FM}-\mathrm{CaCO}_{3}$, praticamente não houve formação destas estruturas. Os meios V8 e STT são aqueles que apresentam maior riqueza nutricional e maior quantidade de carboidratos complexos. Estas características são citadas por diversos autores como capazes de induzir a reprodução de muitos fungos mitospóricos $(5,8)$. O meio V8 é relatado como bom indutor de esporulação em várias espécies do gênero Cercospora (1, 3,6 ). Também o meio STT, uma variação do meio V8, foi indicado por Queiroz \& Menezes (6) como capaz de induzir formação de esporos em Cercospora nicotianae. Comparando ambos os meios, STT mostra-se mais vantajoso do ponto de vista prático, uma vez que o mesmo é composto por um produto nacional facilmente adquirido no Brasil.

Neste estudo, a luz não influenciou a morfologia da colônia, crescimento micelial ou o tempo de formação da colônia. Porém, a quantidade de conídios produzidos sob fotoperíodo foi significativamente superior (Tabela 1). A luminosidade pode exercer efeito indutor ou inibidor sobre a formação de estruturas reprodutivas. Trione \& Leach (9) relataram que, para fungos cuja esporulação é induzida pela luz, este agente físico age diretamente na ativação de enzimas-chave envolvidas na esporogênese. Os mesmos autores afirmam ainda que a quantidade e a qualidade da luz necessária para induzir a formação de estruturas reprodutivas variam de acordo com a espécie fúngica. Beckman \& Paine (1) já haviam relatado a maior produção de conídios quando submeteram um isolado de $C$. zeae-maydis a fotoperío-

Tabela 1. Produção de conídios de Cercospora zeae-maydis submetido a sete meios de cultura e dois regimes luminosos.

\begin{tabular}{cccc}
\hline & \multicolumn{2}{c}{${\text { Esporulação }\left(10^{4} \text { conídios } / \mathrm{mL}\right)^{1}}$} \\
\cline { 2 - 4 } Meio de cultura $^{2}$ & Fotoperíodo Luz seqüencial $^{3}$ & Média \\
STT & 28,62 & 12,36 & $20,50 \mathrm{a}$ \\
V8 & 22,40 & 5,350 & $13,90 \mathrm{a}$ \\
$\mathrm{CO}$ & 0,225 & 0,850 & $0,54 \mathrm{~b}$ \\
$\mathrm{AV}$ & 0,550 & 0,125 & $0,34 \mathrm{~b}$ \\
$\mathrm{BDA}$ & 0,275 & 0,025 & $0,15 \mathrm{~b}$ \\
$\mathrm{FM}$ & 0,850 & 0,00 & $0,42 \mathrm{~b}$ \\
FM-CaCO & 0,425 & 0,025 & $0,22 \mathrm{~b}$ \\
\hline Média & $7,62 \mathrm{~A}$ & $2,68 \mathrm{~B}$ & \\
$\mathrm{CV}_{3}$ & 5,8 & & \\
\hline
\end{tabular}

${ }^{1}$ Concentração de esporos obtida pela adição de $10 \mathrm{~mL}$ de água/placa; médias de cinco repetições; médias seguidas de mesma letra minúscula na coluna e maiúscula na linha não diferem entre si pelo teste de Tukey $(\mathrm{p}=0,01)$.

${ }^{2}$ Meios de cultura agarizados: STT - suco de tomate temperado + $\mathrm{CaCO}_{3}, \mathrm{~V} 8$ - suco de vegetais $\mathrm{V} 8+\mathrm{CaCO}_{3}, \mathrm{CO}$ - água de coco, $\mathrm{AV}-$ farinha de aveia, BDA - batata dextrose, FM - extrato de folhas de milho, $\mathrm{FM}-\mathrm{CaCO}_{3}$ - extrato de folha de milho $+\mathrm{CaCO}_{3}$.

${ }^{3}$ Luz seqüencial $=$ seis dias de luz contínua seguidos por três dias de escuro. 
do 12/12. Estes verificaram que dez dias de claro contínuo seguido de três dias de escuro induziram a esporulação, embora em quantidade inferior aquela do fotoperíodo. A ausência de luz para indução da esporulação já foi relatada para diversos fungos fitopatogênicos como Alternaria brassicae (7), Alternaria solani (5) e Mycosphaerella fijensis (3). Nestes casos, a luz age como foto-inibidor da esporulação. Assim, o fornecimento de luz seguido por um período de escuro é necessário para a completa reprodução destes patógenos. Estudos preliminares (dados não publicados) indicaram que a submissão de colônias de C. zeae-maydis a regime de luz contínua inibiram a formação de esporos, mas não a de conidióforos. Assim, infere-se que esta espécie fúngica necessita de alternância de regime luminoso para completar a reprodução.

Com base no exposto, a melhor condição de incubação visando a produção de conídios de $C$. zeae-maydis deu-se pela associação do regime de luz 12 horas claro/12 horas escuro com os meios de cultura STT ou V8.

\section{REFERÊNCIAS BIBLIOGRÁFICAS}

1. Beckman, P.M.; Payne, G.A. Cultural techniques and conditions influencing growth and sporulation of Cercospora zeae maydis and lesion development in corn. Phytopathology, St. Paul, v.73, n.2, p.286-289, 1983.

2. Griffin, D. H. Fungal physiology. New York: Wiley-Liss, 1994. $458 \mathrm{p}$.
3. Hanada, R.E.; Gasparotto, L.; Pereira, J.C.R. Esporulação de Mycosphaerella fijiensis em diferentes meios de cultura. Fitopatologia Brasileira, Brasília, v.27, n.2, p.170-173, 2002.

4. Hawker, L.E. The physiology of reproduction in fungi. Cambridge: Cambridge University Press, 1957. 128p.

5. Lukens, R.J. Photo-inhibition of sporulation in Alternaria solani. American Journal of Botany, New York, v.50, n.7, p.721-724, 1963.

6. Queiroz, F.M.; Menezes, M. Efeito de meios de cultura e do regime de luz na esporulação de Cercospora nicotianae. Fitopatologia Brasileira, Brasília, v.18, n.4, p.545-547, 1993.

7. Rotem, J.; Bickle, W.; Kranz, J. Effect on environment and host on sporulation of Alternaria macrospora in cotton. Phytopathology, St. Paul, v.79, n.3, p.263-266, 1989.

8. Strandberg, J.O. Isolation, storage, and inoculum production methods for Alternaria dauci. Phytopathology, St. Paul, v.77, n.7, p.10081012, 1987.

9. Trione, E.J.; Leach, C.M. Light-induced sporulation and sporogenic substances in fungi. Phytopathology, St. Paul, v.59, n.8, p.10771083, 1969.

10. Ward, J.M.J.; Stromberg, E.L.; Nowell, D.C.; Nutter JR, F.W. Gray leaf spot - A disease of global importance in maize production. Plant Disease, St. Paul, v.83, n.10, p.884-895, 1999. 